\title{
ANALISIS GANGGUAN FONOLOGI DAN VARIASI PELAFALAN FONEM /R/ PADA PENDERITA CADEL
}

\author{
Andriyana \\ Pendidikan Bahasa Indonesia \\ Pasca Sarjana Universitas Muhammadiyah Malang \\ Andriyana03@gmail.com
}

\begin{abstract}
ABSTRAK: Fonologi sebagai kajian bunyi mentanskripsikan bunyi secara detail secara fonetik dari yang dihasilkan artikulator pembicara. Penelitian sebelumnya berkaitan dengan cadel cenderung memukul rata karena hanya menggunakan transkripsi ortografis dan fonemis namun tidak sampai melakukan transkripsi fonetik. Untuk penyebab dari cadel itu sendiri sudah banyak dibahas oleh peneliti lain sehingga penulis hanya melihat tanpa meneliti lebih dalam penyebab dari cadel. Gangguan cadel yang dialami oleh Aden Eka Pradana dan Ilham Maulana Irsyad yang akan dilihat perbedaan dan variasi pengucapan fonem $/ \mathrm{r} /$ yang mereka ucapkan untuk membedakan pendapat umum tentang cadel yang hanya mengubah fonem $/ \mathrm{r} /$ menjadi /1/. Penelitian ini megunakan metode kualitatif dengan pendekatan studi kasus dengan proses pencarian data menggunakan wawancara terbuka untuk mendalami kasus cadel dan wawancara tertutup untuk menguji pengucapan fonem /r/ dengan posisinya dalam kata. Data tersebut kemudian diolah menggunakan teknik Miles dan Huberman. Hasil penelitian menunjukan posisi /r/ dan kondisi individu membedakan pelafalan $/ \mathrm{r} /$ sehingga pada tes menggunakan fonem konsonan partisipan pertama menimbulkan bunyi aspirasi dan partisipan kedua menimbulkan retopleks. Tes kedua dengan menggunakan kluster kembali memiliki perbedaan pada partisipan pertama menyebutkan dengan sempurna sementara partisipan kedua masih memiliki gangguan yaitu lateral release. Hal ini membuktikan bahwa posisi dan jenis fonem $/ \mathrm{r} /$ mempengaruhi pengucapan pada penderita cadel.

KATA KUNCI: cadel; fonologi; gangguan fonologi; trill apikoalveolar;
\end{abstract}

ANALYSIS OF PHONOLOGICAL DISORDERS AND VARIATIONS OF FONEM /R/ IN LISP PATIENTS

\begin{abstract}
Phonology as the study of sound describes sounds in phonetic detail from the speaker articulator. Previous research related to slurred tended to flatten because it only used orthographic and phonemic transcription but did not make phonetic transcription. For the cause of lisp itself has been widely discussed by other researchers so that the authors only look without examining deeper the causes of lisp. Slurred disorder experienced by Aden Eka Pradana and Ilham Maulana Irshad that will be seen differences and variations in pronunciation of the phonemes $/ \mathrm{r} /$ they say to distinguish general opinions about lisp which only changes the phoneme /r/ to /1/. This study uses a qualitative method with a case study approach with the process of finding data using open interviews to explore slurred cases and closed interviews to test phoneme $/ \mathrm{r} /$ pronunciation with its position in words. The data is then processed using Miles and Huberman techniques. The results showed that the position $/ \mathrm{r} / \mathrm{and}$ individual conditions differentiate pronunciation /r/ so that in the test using the consonant phoneme the first participant raises the sound of aspiration and the second participant gives rise to retoplex. The second test using the cluster again has a difference where the first participant mentions perfectly while the second participant still has the disorder namely lateral release. This proves that the position and type of phoneme $/ \mathrm{r} /$ affect pronunciation in slurred sufferers.

KEYWORDS: apicoalveolar trill; lisp; phonology; phonological disorders;

\begin{tabular}{lccc}
\hline Diterima: & Direvisi: & Distujui: & Dipublikasi: \\
10-04-2020 & $18-09-2020$ & $21-09-2020$ & $28-10-2020$ \\
Pustaka & $:$ Andriyana (2020). Analisis Gangguan & Fonologi dan Variasi Pelafalan Fonem /R/ Pada \\
& Penderita Cadel. Fon : Jurnal Pendidikan Bahasa dan Sastra Indonesia, 16(2), 57-64. \\
DOI $\quad:$ https://doi.org/10.25134/fjpbsi.v16i2.2700 & \\
\hline
\end{tabular}
\end{abstract}

\section{PENDAHULUAN}

Fonologi sebagai satuan terkecil dalam susunan linguistik memiliki peran penting dalam komunikasi. Fonologi menjadi dasar pembentukan satuan bahasa selanjutnya sehingga struktur morfologi 
bisa terbentuk, dan selanjutnya terus berurut ke sintaksis dan wacana. Kajian yang membedakan makna ini dalam fonologi dinamakan kajian fonetetik. Menurut Chaer (2009, Hlm. 3) Secara umum fonetik bisa dijelaskan sebagai cabang fonologi yang mengkaji bunyibunyi bahasa tanpa memperhatikan statusnya, apakah bunyi-bunyi bahasa itu dapat membedakan makna (kata) atau tidak. Sementara itu kajian lebih dalam tentang fonologi yang mengatur bagaimana bunyi dari setiap fonem yang ada diatur dalam kajian fonemik yang menurut Chaer (2009, Hlm. 3) fonemik adalah cabang kajian fonologi yang mengkaji bunyi-bunyi bahasa dengan memperhatikan fungsinya sebagai pembeda makna (kata).

Kajian tentang fonetik dan fonemik ini sangat berkaitan erat dengan sebuah analisis bunyi bagi mereka yang memiliki gangguan berbahasa. Chaer (2019, Hlm. 7) berpendapat bahwa hasil kajian fonologi juga diperlukan dalam bidang klinis yaitu dalam membantu mereka yang mendapat hambatan dalam berbicara maupun mendengar. Artikulator sebagai penghasil alat ucap manusia adalah sumber kajian gangguan fonologi yang jika ditranskripsi lebih jelas ke satuan fon dan alofon harus ditranslasikan secara fonetis tidak hanya otograsfis. Hal ini bertujuan agar bunyi yang dikeluarkan oleh penutur lebih detail pentranskripsianya dan memberikan setiap perbedaan pada fon dan alofon yang mucul. Contohnya saja dalam fonem $/ \mathrm{u} /$ yang direalisasikan dalan alofon $[\mathrm{u}]$ dan [U] dalam kata <buku> buku dan <libur $>$ [libUr] dimana $[\mathrm{u}]$ adalah silabel tak berkoda (terbuka) dan [U] silabel berkoda (tertutup).

Fonem yang seharusnya dibunyikan normal pada kasus tertentu dengan berbagai pengaruh seperti stoke sebagai penyakit berat mengalami gangguan dan menimbulkan ketidak jelasan pada pendengar ketika melakukan proses dekoding. Penelitian seperti yang dilakukan Yuliastuti (2020) dengan judul Lsvt Loud Meningkatkan Kemampuan Komunikasi Verbal Pasien Stroke Iskemik Dengan Disartria Di Rsi Jemursari Surabaya. Dewi (2019) Perubahan Bunyi Bahasa Pada Penderita Afasia Wernicke (Kajian pada Pasien Mr. D). Johan (2018) Gangguan Berbahasa Pada Penderita Strok Suatu Kajian: Neurolinguistik. Purba (2018) Pemerolehan Fonologi Anak Usia 6 Tahun Dengan Riwayat Kejang Demam (Studi kualitatif pemerolehan fonologi pada Nazwa). Adalah contoh ganguan berbahasa yang didalamnya terdapat kajian fonologi dan sumber gangguan berbahasa dengan penyakit tertentu. Penelitian lain yang membahas fonologi dilakukan oleh Devianty (2016) Pemerolehan Bahasa dan Gangguan Bahasa pada Anak Usia Batita. Maharany (2016) Gejala Fonologis Bahasa Indonesia pada Anak Usia 3-4 Tahun di Paud Permata Hati Kota Kendari. Amaliah (2017) Pemerolehan Kompetensi Fonologis dan Gangguan Pemroduksian Ujaran pada Anak Berusia 3 Sampai 4 Tahun. Penelitian Devianty (2016), Maharany (2016) dan Amaliah (2017) membahas objek penelitian berusia balita dan merupakan khazanah yang penulis pelajari dalam pendalaman penyebab gangguan fonologi pada kanak-kanak.

Dalam kasus dilapangan terdapat kasus cadel pada orang dewasa yang artikulatornya dapat dikatakan sudah sempurna dan tidak mungkin berkembang lagi memiliki gangguan pada pengucapan fonem $/ \mathrm{r} /$ sehingga bunyi yang seharusnya tril apikoalveolar malah menjadi /1/ yang lateral apiko alveolar. Dan selanjurnya setelah diamati narasumber yang bernama Ilham Maulana Irsyad (23 Tahun) dan Aden Eka Pradana (22 tahun) memiliki perbedaan pengucapan fonem $/ \mathrm{r} /$ yang itu harus dibuktikan secara fonetis sehingga apa yang diucapkan oleh dua narasumber 
ini dapat tertranskripsikan dengan baik. Arsal (2012 Hlm. 156-166) membuat penelitian berjudul Analisis Pedigree Cadel (Studi Kasus Beberapa Kabupaten di Sulawesi Selatan) membahas tentang penyebab cadel dari sisi genetis dan menyimpulkan bahwa penyebab cadel ini adalah (1) Cadel dapat disebabkan oleh faktor keturunan. (2) Pola pewarisan gen cadel adalah resesif autosomal. Dalam jurlanya penyebab cadel ini sendiri dikemukakan secara klinis sebagai gangguan disastri.

Menurut dr. Lily Sidiarto dalam

Arsal (2012) cadel adalah salah

satu bentuk disartri yaitu sebutan

untuk gangguan artikulasi

(pengucapan kata) yang

disebabkan oleh gangguan

struktur atau gangguan fungsi

dari organ artikulasi. Cadel dapat

disebabkan oleh gangguan

struktur antara lain karena ukuran

lidahnya relatif pendek atau

kelainan pada otot yang terdapat

di bawah lidah. Adanya kelainan

kedua otot tadi bisa menyebabkan

gerakan lidahmenjadi kurang baik.

Dalam kasus lain partisipan bernama Yogi dalam Dewi, Sastra (2015) dengan penelitian berjdul Gangguan Fonologis Penderita Ankyloglossia Penutur Bahasa Melayu Riau ganguan cadel ini desebabkan oleh tongue-tie dimana Frenulum linguae yang berada di bagian bawah lidah menyebabkan ujung lidah tidak mampu bekerja dengan baik, seperti kerja lidah anak nonAnkyloglossia. Penelitian tentang cadel ditulis juga oleh Janella, Muzzamil, \& Syahrani (2019) yang meneliti anak usia sekolah dasar dengan keterangan bahwa pengucapan $/ \mathrm{r} /$ adalah kompetensi yang harus dimiliki anak kelas 1 semester 2 sekolah dasar. Dalam penelitian ini peneliti hanya mentrankripsika secara ortografis yang hanya mengambil data fonem apa saja yang sudah dikuasai dan belum dikuasai oleh objek penelitian. Dalam penelitian ini belum ada bahasan tentang perbedaan secara fonemis atau variasi dari cadel itu sendiri. Penelitian lebih spesifik pada orang dewasa dilakukan oleh Matondang (2019) dengan objek penelitian berusia 27 tahun. Penelitian berjudul Analisis Gangguan Berbicara Anak Cadel (Kajian Pada Perspektif Psikologi dan Neurologi) ini sesuai judulnya lebih mengedepankan aspek psikologi dan neorologi, dengan transkripsi otografis. Simpulan penelitian ini penyebab dari cadel tersebut adalah faktor pisikologis ketika kanak-kanak dari ibunya yang mempengaruhi neorologis objek penelitian. Kasus yang lebih bervariasi pada pengucapan fonem /r/ ditulis oleh Rodzi, \& Jaafar (2018) yang berjudul Kajian Fonologi Kesalahan Bunyi Dalam Bahasa Kanak-Kanak dengan hasil temuan perubahan konsonan [r] yang ditemukan (a) konsonan [r] digantikan dengan konsonan $[\mathrm{\gamma}]$, (b) konsonan [r] digantikan dengan konsonan [w] dan (c) konsonan [r] digantikan dengan konsonan [1].

Fonem $/ \mathrm{r} /$ yang merupakan konsonan ini posisi dalam katanya bisa menduduki semua posisi yaitu awal, tengah, dan akhir contoh: raja, urat dan lebar (Chaer, 2009 Hlm. 91). Dilihat dari proses fonologisnya konsonan juga memiliki gugus konsonan (kluster) yang merupakan konsonan rangkap. Khusus untuk fonem $/ \mathrm{r} /$ gugus konsonannya adalah /br/, /dr/, /fr/, /pr/, /skr/, dan /tr/. Kesemua gugus konsonan ini posisinya dalam kata dapat berada di awal dan ditengah namun tidak bisa berada di akhir. Dan dua gugus konsonan yang hanya berada di awal yaitu /gr/, / kr/, dan /sr/. Dengan adanya teori ini peneliti akan melihat bunyi fonem $/ \mathrm{r} /$ yang dihasilkan partisipan dilihat dari posisi dan setiap varian gugus fonem untuk melihat posisi $/ \mathrm{r} /$ dalam kata 
berpengaruh atau tidak. Dan seperti penelitian gugus fonem yang dilakukan Peishi, Sumarti, \& Rusminto, (2018) pada penutur mandarin yang melihat ketepatan pelapalan pada semua kluster.

Dari beberapa penelitian yang sudah dikemukakan di atas dengan berbagai penyebabnya, peneliti melihat bahwa penelitian cadel ini lebih banyak dilakukan pada anak-anak yang secara fisik alat artukulator mereka masih bisa berubah atau ada kemungkinan sembuh. Bahkan bagi mereka yang hanya mempunyai beban psikologis dan neurologis sangat bisa sekali berubah meski sudah berusia dewasa. Namun Matondang (2019) tidak mengemukakan saran untuk cara penyembuhan mereka yang menderita cadel karena beban pisikologis dan neorologis. Para peneliti dalam penelitian cadel rata-rata bahkan dari semua penelitian cadel yang penulis temui tidak mentrankripsikan secara fonetis dengan kajian mendetail dari pengucapan fonem $/ \mathrm{r} /$ itu sendiri. Peneliti ingin melihat perbedaan pengucapan fonem dari kedua partisipan karena dalam istilah sunda atau istilah desa tempat saya tinggal ada istilah cadel dan ada istilah garap yang memiliki perbedaan. Dua partisipan ini Aden dianggap garap dan ilham dianggap cadel.

Dengan adanya istilah lokal tersebut peneliti ingin membuktikan kedua perbedan tersebut dan mencari lebih detail dari pengucapan fonem $/ \mathrm{r} /$ pada orang cadel dengan melakukan studi kasus pada dua partisipan yang ditemui. Karena pada kasus cadel peneliti belum menemui kasus bunyi yang berbeda atau mendapatkan istilah yang lain dari cadel ini. Peneliti juga akan melihat penyebab gangguan tersebut sebagai acuan bagi pemunculan saran agar penderita gangguan cadel bisa sembuh.

\section{METODE}

Metode penelitian yang digunakan dalam penelitian ini adalah deskriptip kualitatif yang dijelaskan . Bogan dan Tailor dalam Pentury (2017 Hlm. 19) bahwa penelitian deskriptif adalah Prosedur penelitian yang menghasilkan data deskriptif berupa katakata tertulis atau lisan dari orang-orang atau perilaku yang dapat diamati. Adapun pendekatan yang digunakan dalam penelitian ini adalah studi kasus yang menurut Dhofir dalam Hidayat (2014) Studi kasus adalah studi yang mendalam (eksploratif) dan menyeluruh (integral) mengenai suatu obyek tertentu yang menarik secara khusus dan tersendiri. Adapun tujuan dari penelitian deskriptif kualitatif adalah untuk menggambarkan, meringkas berbagai kondisi, berbagai situasi, atau berbagai fenomena realitas sosial yang ada di masyarakat yang menjadi objek penelitian dan berupaya menarik realitas itu ke permukaan sebagai suatu ciri, karakter, sifat, model, tanda, atau gambaran tentang kondisi, situasi, ataupun fenomena tertentu (Bungin, $2007 \mathrm{Hlm}$. 68).

Teknik perolehan data dalam penelitian ini adalah teknik wawancara, dengan pembagian wawancara dibagi menjadi dua sesi yaitu wawancara terbuka berkaitan dengan penyebab cadel pada partisipan dan wawancara tertutup berupa percobaan pelafalan /r/ pada kata yang disiapkan oleh peneliti. Adapun yang menjadi partisipan disini adalah Aden Eka Pradana (AEP) 22 tahun dan Ilham Malulana Irsyad 23 tahun (IMI) yang merupakan mahasiswa Pendidikan Bahasa dan Sastra Indonesia Fakultass Keguruan dan Ilmu Pendidikan.

Dalam penelitian ini penulis memilih analisis data model Miles dan Huberman yang dikemukakan dalam Sugiyono (2019 hlm. 438-448) teknik ini dipilih karena lebih interaktif dan sesuai dengan tema penelitian yang 
membutuhkan deskripsi dan wawancara yang lebih intens dan mendalam pada narasumber. Adapun langkah dari teknik analisis data model Miles dan Huberman adalah data coletion, data reduction, data display, dan conclusion drawing/verification.

\section{HASIL DAN PEMBAHASAN}

Dari penelitian yang dilakukan ditemukan hasil wawancara terbuka dari dua narasumber berkaitan dengan penyebab pertanyaan pertama Tahukan alasan dan penyebab cadel. Kedua narasumber baik AEP dan IMI tidak mengetahui penyebab dan alasan mereka memiliki gangguan cadel. IMI lebih jelas menjawab pada pertanyaan ini dengan menjelaskan kalau lidahnya tidak sampai kelangit-langit (velar). AEP menjelaskan kondisi lidahnya memang pendek, tapi ketika pengucapan $/ \mathrm{r} /$ sampai kelangitlangit hanya saja tidak bisa berggetar dan susah, namun lebih jelas dari AEP walaupun sampai area velar hanya dalam kondisi tertentu dan itupun ujungnya saja dengan sedikit dipaksa.

Pertanyaan kedua berkaitan dengan percobaan atau cara yang dilakukan untuk menyembuhkan. hal tersebuh dijawab oleh AEP,

"Saya sudah banyak
melakukan saran teman-teman

untuk melakukan beberapa senam

lidah seperti berulangkali mengucapkan / $r /$ dan mengucapkan kata yang banyak / $r$ / seperti laler luar leor mapai areuy tetap saja tidak bisa dan tidak merubah cadel saya”.

IMI menjawab pertanyaan kedua dengan menjelaskan bahwa dia pernah diurut dan ditarik lidahnya yang katanya supaya panjang dan bisa mencapai langitlangit ketika pengucapan tril apikoalveolar. Ternyata tetap tidak bisa merubah cadel.
Pada pertanyaan ketiga tentang pengaruh cadel dalam kehidupan seharihari. AEP dan IMI menjelaskah pengalaman yang sama bahwa beberapa teman sering mengejek hal ini, dan jika sedang berbicara di depan kelas atau mengobrol seringkali diberhentikan hanya untuk membenarkan huruf $/ \mathrm{r} /$ yang itu berpengaruh jika sedang presentasi atau penampilan tertentu di depan kelas.

Pertanyaan keempat adalah apakah mereka pernah berhasil mencapkan /r/ dengan tril apikoalveolar. AEP dengan ragu menjawab pernah tapi susah dan IAD menjawab sangat sulit. Jawaban AEP yang menjawab pernah dijelaskan lagi bahwa ketika itu sedang melakukan senam lidah dengan pengucapan huruf /r/.

Selanjutnya adalah wawancara tertutup tentang ujicoba pengucapan fonem /r/ berdasarkan posisinya pada kata. AEP mendapatkan hasil pada table 1 berikut ini.

Tabel 1. Pengucapan Huruf "R" oleh AEP

\begin{tabular}{|c|c|c|c|}
\hline \multicolumn{4}{|c|}{ Huruf "R" di awal } \\
\hline No & Ortografis & Fonetik & Fonemis \\
\hline 1 & Robot & {$\left[\mathrm{r}^{\mathrm{h}} \mathrm{O}\right.$ 'bot $]$} & $/ \mathrm{r}(\mathrm{h}) \mathrm{O}^{\prime} \mathrm{b}(\mathrm{\partial}) \mathrm{t} /$ \\
\hline 2 & Rumah & {$\left[\mathrm{r}^{\mathrm{h}} \mathrm{um} \mathrm{Ah}\right]$} & /r(h)umah/ \\
\hline \multicolumn{4}{|c|}{ Huruf " $R$ " di tengah } \\
\hline No & Ortografis & Fonetik & Fonemis \\
\hline 1 & Berjalan & [ber ${ }^{\mathrm{h}}$ jalan] & /ber(h) jalan \\
\hline 2 & Terang & {$\left[\operatorname{trr}^{\mathrm{h}} \mathrm{Ang}\right]$} & $/ \mathrm{t}(\partial) \mathrm{r}(\mathrm{h})$ 'ang \\
\hline \multicolumn{4}{|c|}{ Huruf "R" di akhir } \\
\hline No. & Ortografis & Fonetik & Fonemis \\
\hline 1 & Motor & {$\left[\mathrm{mO}^{\prime} \operatorname{tor}^{\mathrm{h}}\right]$} & $/ \mathrm{mO}^{\prime} \mathrm{t}(\mathrm{O}) \mathrm{r}(\mathrm{h}) /$ \\
\hline 2 & Kantor & [k'Antor $\left.{ }^{h}\right]$ & $/ \mathrm{k}^{\prime} \mathrm{nn}^{\prime}(\mathrm{O}) \mathrm{r}(\mathrm{h}) /$ \\
\hline
\end{tabular}

Dari tes yang dilakukan kepada AEP ditemukan hasil bahwa pengucapan $/ \mathrm{r} /$ oleh partisipan terpengaruh oleh aspirasi sehingga pengucapan /r/ bercampur dengan hembusan nafas yang keras sehingga pengucapan / $/$ / oleh AEP terdengar seperti bercampur dengan $/ \mathrm{h} /$. Adanya aspirasi pada bunyi fonem $/ \mathrm{r} / \mathrm{ini}$ stabil pada tes yang dilakukan seperti pada tabel Tabel 1. Pengucapan Huruf "R" oleh AEP. Adanya aspirasi AEP ternyata masih 
mengucapkan /r/ secara apikoalveolar hanya saja tidak getar (tril).

Gangguan fonologis yang dialami oleh AEP ini ternyata berpengaruh pada pengucaran $/ \mathrm{r} /$ yang posisinya ditengah kata jika dilihat dari unsure supra segmental. Hasil tes menunjukan pada kata <berjalan> diucapkan dengan primary stress (') atau jeda ketika mendapat fonem $/ \mathrm{r} /$ ditengah dengan transkripsi fonetik sebagai berikut [ber ${ }^{\mathrm{h}}$ jalan]. Hasil yang sama juga ditunjukan pada kata <terang $>$ yang yang mendapatkan jeda setelah muncul $/ \mathrm{r} / \mathrm{di}$ tengah kata yang jika secara fonetis seperti ini [tər ${ }^{\mathrm{h}^{\mathrm{h}}} \mathrm{Ang}$ ]. Pengucapan $/ \mathrm{r} / \mathrm{di}$ awal dan di akhir ternyata konsisten mendapatkan aspirasi dan tidak menimbulkan jeda. Berbeda seperti /r/ yang ditengah ketika sudah mendapatkan aspirasi tetap memiliki jeda sehingga $/ \mathrm{r} /$ yang diucapkan AEP dapat pada tengah kata ditranskripsikan sebagai berikut $\left[\mathrm{r}^{\mathrm{h}}\right]$.

Pada hasil tes yang dilakukan pada IMI ternyata memiliki perbedaan yang cukup besar yang ditunjukan dalam tabel 2 bahwa pengucapan /r/ menjadi lateral apikoalveolar. Yang bisa dilihat transkripsinya sebagai berikut.

Tabel 2. Pengucapan Huruf "R" oleh IMI

\begin{tabular}{|c|c|c|c|}
\hline \multicolumn{4}{|c|}{ Huruf "R" di awal } \\
\hline No. & Ortografis & Fonetik & Fonemis \\
\hline 1 & Robot & {$\left[{ }^{\mathrm{r}} \mathrm{lOb}{ }^{2}\right]$} & $/ 1 \mathrm{Ob}(\mathrm{\supset}) \mathrm{t} /$ \\
\hline 2 & Rumah & [ $\left.{ }^{\mathrm{r}} \operatorname{lum} \mathrm{Ah}\right]$ & / lumah/ \\
\hline \multicolumn{4}{|c|}{ Huruf "R" di tengah } \\
\hline No. & Ortografis & Fonetik & Fonemis \\
\hline 1 & Berjalan & [be ${ }^{\mathrm{r}} \mathrm{l}^{\prime}$ jalan] & /bel'jalan/ \\
\hline 2 & Terang & {$\left[\mathrm{to}^{\mathrm{r}} \mathrm{l}^{\prime} \mathrm{Ang}\right]$} & $/ \mathrm{t}(\partial) l^{\prime}$ ang/ \\
\hline \multicolumn{4}{|c|}{ Huruf "R" di akhir } \\
\hline No. & Ortografis & Fonetik & Fonemis \\
\hline 1 & Motor & {$\left[\mathrm{mOtsl}^{\mathrm{r}}\right]$} & $/ \mathrm{mOt}(\mathrm{\supset}) 1(\mathrm{r}) /$ \\
\hline 2 & Kantor & {$\left[\mathrm{k}^{\prime} A n t \mathrm{ll}^{\mathrm{r}}\right]$} & $/ \mathrm{k}$ ant(つ)l(r)/ \\
\hline
\end{tabular}

Hasil yang diperoleh dari IMI dari tabel ditas menunjukan bahwa bunyi /r/ mengalami perubahan fonemem dari trill apikoalveolar menjadi lateral apikoalveolar atau /1/ namun disertai oleh retopleks. Pada /r/ yang posisi dalam katanya di awal dan di tengah, letak retofleks sebelum $/ \mathrm{r} /$ atau yang dibunyikan /1/ seperti pada kata <berjalan> yang dilafalkan seperti ini [be ${ }^{\mathrm{r}} \mathrm{l}^{\prime} \mathrm{jalan}$ ]. Namun kasus berbeda terjadi pada /r/ di akhir kata yang menempatkan retofleks sesudah kata seperti dalam kata <kantor $>$ yang dilafalkan [k'Antıl $\left.{ }^{\mathrm{r}}\right]$. Sama seperti AEP hasil pada IMI juga menunjukan bahwa pada /r/ yang ditengah kata menimbulkan primary stress yang jika ditranskripsikan IMI mengucapkannya seperti ini [ $\left.{ }^{\mathrm{r}}{ }^{\prime}\right]$.

Jika pada uji coba pertama peneliti menggunakan fonem konsonan, pada uji coba yang kedua peneliti melihat pengucapan $/ \mathrm{r} / \mathrm{jika}$ berada dalam gugus konsonan (Kluster). Yang ternyata fakta menarik didapatkan pada AEP. Hasil tes AEP yang dilakukan pada tahap kedua adalah sebagai berikut.

Tabel 3. Pengucapan gugus konsonan Huruf "R" oleh AEP

\begin{tabular}{|l|l|l|l|}
\hline No. & Ortografis & Fonetik & Fonemis \\
\hline 1 & Drama & {$\left[\mathrm{drA}^{\prime} \mathrm{ma}\right]$} & $/ \mathrm{drama} /$ \\
\hline 2 & Keprok & {$[\mathrm{k}$ 'əprOk] } & $/ \mathrm{k}($ (ə)prOk/ \\
\hline
\end{tabular}

Hasil tes pada gugus konsonan oleh AEP ternyata tidak menemukan hambatan, AEP lancar mengucapkan /r/ pada konsonan rangkap. /r/ pada konsonan rangkap yang diucapkan secara langsung baik diawal ataupun ditengah dilafalkan dengan benar.

Tabel 4. Pengucapan gugus konsonan Huruf "R" oleh IMI

\begin{tabular}{|l|l|l|l|}
\hline No. & Ortografis & Fonetik & Fonemis \\
\hline 1 & Drama & {$\left[\mathrm{d}^{\prime} \mathrm{ra}^{\prime} \mathrm{ma}\right]$} & $\mathrm{D}(\mathrm{l}) \mathrm{rama}$ \\
\hline 2 & Keprok & $\left.\mathrm{k}^{\prime} \mathrm{p}^{\prime} \mathrm{rOk}\right]$ & $\mathrm{k}(\mathrm{\partial}) \mathrm{p}(\mathrm{l}) \mathrm{rOk}$ \\
\hline
\end{tabular}

Pada hasil tes kedua yang dilakukan oleh IMI. ternyata IMI masih mengalami gangguan fonologi pada gugus konsonan yang seperti dalam tabel terlihat bahwa adanya lateral release [']. dilihat dari hasil tersebut lateral release yang dilafalkan oleh IMI ternyata berbeda jika gugus 
konsonannya di awal dan di tengah. Jika gugus fonem di awal lateral release sebelum / $\mathrm{r}$ / atau pada transkripsi [1] dan jika ditengah kata berada setelah $/ \mathrm{r} /$ atau pada transkripsi [1].

\section{KESIMPULAN}

Dari hasil penelitian yang dilakukan penulis menarik kesimpulan bahwa gangguan cadel disebabkan oleh faktor artikulator sehingga mereka yang mengalami gangguan ini tidak bisa mengucapkan /r/ secara trill apikoalveolar seperti orang Indonesia pada umumnya. Kondisi ini juga mempengaruhi kehidupan sehari-hari yang menimbulkan dampak pisikologi pada penderita.

Variasi pengucapan cadel akan berbeda pada posisi /r/ dalam kata dan tergantung kondisi penderita. AEP mengucapkan $/ \mathrm{r} /$ aspirasi dan konsisten melafalkan dengan $\left[\mathrm{r}^{\mathrm{h}}\right]$ ternyata pada fonem konsonan yang tidak mengalami gangguan ketika $/ \mathrm{r} /$ sebagai gugus konsonan atau kluster. Hal ini membuktikan bahwa posisi fonem dan jenis fonem sangat mempengaruhi. Hasil pada IMI pun mengalami dua perbedaan jika pada fonem konsonan memiliki konstan mendapatkan retofleks pada gugus konsonan IMI mengucapkannya dengan lateral release.

Dalam penelitian ini membuktikan bahwa cadel tidak hanya mengucapkan $/ \mathrm{r} /$ menjadi /1/ tapi dalam kajian fonologi hal itu menjadi kompleks dan bervariasi sehingga apa yang didengar oleh seorang akademisi harus berbeda dengan orang umum yang tidak mengetahui teori dan menyamaratakan pengucapan setiap fonem.

Untuk penelitian selanjutnya dan pengembangan ilmu fonologi pada gangguan cadel transkripsi fonetik penulis memiliki saran untuk memprioritaskan dalam penelitian karena akan dapat mengambarkan gangguan dan variasi pelafalan yang dilafalkan partisipan. Hal ini juga berlaku pada penelitian fonologi yang lain agar pendeskripsian dan penerjemahan fonem dengan unsur segmental dan suprasegmental dapat dibaca dengan baik.

\section{DAFTAR PUSTAKA}

Amaliah, M. N. (2017). PEMEROLEHAN KOMPETENSI FONOLOGIS DAN GANGGUAN PEMRODUKSIAN UJARAN PADA ANAK BERUSIA 3 SAMPAI 4 TAHUN. Caraka: Jurnal Pendidikan Bahasa dan Sastra Indonesia serta Bahasa Daerah, 6(2), 47.

Arsal, A. F. (2012). Analisis Pedigree Cadel (Studi Kasus Beberapa Kabupaten di Sulawesi Selatan). Sainsmat: Jurnal Ilmiah Ilmu Pengetahuan Alam, 1(2), 156-166.

Bugin, Burhan. (2007). Penelitian Kualitatif. Jakarta : Prenada Media Grup

Chaer, A. (2009). Fonologi Bahasa Indonesia. Rineka Cipta.

Devianty, R. (2016). Pemerolehan bahasa dan gangguan bahasa pada anak usia batita. RAUDHAH, 4(1).

Dewi, M. I. N. (2019). PERUBAHAN BUNYI BAHASA PADA PENDERITA AFASIA WERNICKE (KAJIAN PADA PASIEN MR. D). ENSAINS JOURNAL, 2(2), 68-74.

Dewi, Y. K., \& Sastra, G. (2015). GANGGUAN FONOLOGIS PENDERITA ANKYLOGLOSSIA PENUTUR BAHASA MELAYU RIAU. Puitika, 11(1), 11-25.

Hidayat, A. (2015). VARIASI BAHASA BERDASARKAN JENIS KELAMIN DI DESA MATANGAJI KECAMATAN SUMBER KABUPATEN CIREBON. FON: Jurnal Pendidikan Bahasa dan Sastra Indonesia, 5(2). 
Janella, T., Muzzamil, A. R., \& Syahrani, A. KAJIAN PSIKOLINGUISTIK TERHADAP GANGGUAN MEKANISME BERBICARA (STUDI KASUS RAISYA DAN ATHAYA). Jurnal Pendidikan dan Pembelajaran Khatulistiwa, 8(9).

Johan, M., \& Susanto, A. (2018, October). Gangguan berbahasa pada penderita strok suatu kajian: Neurolinguistik. In Prosiding Seminar Nasional Ilmu Sosial dan Teknologi (SNISTEK) (No. 1, pp. 103-108).

Maharany, A. F. (2016). Gejala fonologis bahasa indonesia pada anak usia 3-4 tahun di paud permata hati kota kendari. JURNAL BASTRA, 2(1).

Matondang, C. E. H. (2019). ANALISIS GANGGUAN BERBICARA ANAK CADEL (Kajian Pada Perspektif Psikologi dan Neurologi). Bahastra: Jurnal Pendidikan Bahasa dan Sastra Indonesia, 3(2), 49-59.

Peishi, N., Sumarti, S., \& Rusminto, N. E. (2018). Ketepatan Pelafalan Kluster Dan Deretan Konsonan Bahasa Indonesia Oleh Penutur Mandarin. J-SIMBOL (Bahasa, Sastra, dan Pembelajarannya), 6(1).
Pentury, H. J. (2018). Pengembangan Literasi Guru PAUD Melalui Bahan Ajar Membaca, Menulis dan Berhitung di Kecamatan Limo dan Cinere. DIKEMAS (Jurnal Pengabdian Kepada Masyarakat), 1(1).

Purba, H. S. R. (2018). PEMEROLEHAN FONOLOGI ANAK USIA 6 TAHUN DENGAN RIWAYAT KEJANG DEMAM (Studi kualitatif pemerolehan fonologi pada Nazwa). LINGUISTIK: Jurnal Bahasa dan Sastra, 3(1), 15-24.

Rodzi, N. S. M., \& Jaafar, S. R. S. (2018). Kajian Fonologi Kesalahan Bunyi Dalam Bahasa Kanak-Kanak (A Phonological Study of Sound Errors in Children's Utterances). e-Bangi, 15(2).

Sugiyono. (2017). Metode penelitian kuantitatif dan kualitatif dan $R \& D$. Bandung : Alfabeta.

Yuliastuti, R. A. (2020). LSVT LOUD MENINGKATKAN KEMAMPUAN KOMUNIKASI VERBAL PASIEN STROKE ISKEMIK DENGAN DISARTRIA DI RSI JEMURSARI SURABAYA. Infokes, 10(1), 206-213. 